ARTICLE

\title{
Nutritional support of children with chronic liver disease
}

E D Nel, ${ }^{1}$ MB ChB, MMed (Paed), BSc Hons (Epidemiology); A J Terblanche, ${ }^{2}$ MB ChB, Dip Allerg (SA), MMed (Paed), FCPaed (SA), Cert Gastroenterol (SA) Paed, Dip Pal Med (Paed) (SA)

${ }^{1}$ Department of Paediatrics and Child Health, Faculty of Medicine and Health Sciences, Stellenbosch University, Cape Town, South Africa

${ }^{2}$ Department of Paediatrics and Child Health, Faculty of Health Sciences, University of Pretoria, South Africa

Corresponding author: E D Nel (edn@sun.ac.za)

Anorexia, malabsorption and metabolic derangements contribute to the malnutrition that occurs in most children with chronic liver disease. Nutritional support should be started early in the management of these children with the co-operation of a paediatric dietitian to improve quality of life and decrease post-transplant mortality.

Nutritional assessment entails a detailed dietary history, physical examination and anthropometry. Weight-based anthropometric measures are unreliable while mid-upper-arm circumference and skinfold thickness provide more reliable estimates of nutritional status. Special investigations such as serum vitamin levels and skeletal X-rays further guide management.

High energy (130 - 150\% of recommended daily intake (RDI)) and protein (3 - $4 \mathrm{~g} / \mathrm{kg} /$ day) intakes are recommended. Diets are usually enriched with medium-chain fatty acids because of their better absorption in cholestatic liver disease. High-dose fat-soluble vitamin supplements are given while care is taken to avoid toxicity. Initial doses are two to three times the RDI and then adjusted according to serum levels or international normalised ratio (INR) in the case of vitamin $\mathrm{K}$.

Children with good appetites are fed orally. Feeds should be more regular than for other children to avoid prolonged periods of fasting and improve energy intake. Some children require supplementary nasogastric feeds to increase energy intake and avoid overnight fasting.

S Afr Med J 2015;105(7):607. DOI:10.7196/SAMJnew.7783

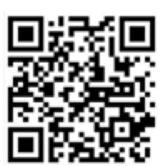

A large variety of conditions cause chronic liver disease (CLD) in children. In infants, biliary atresia is the most common cause followed by inherited metabolic disease, genetic abnormalities, and other biliary abnormalities. Auto-immune hepatitis, nonalcoholic fatty liver disease, chronic viral hepatitis and inherited metabolic disease are leading causes in older children.

The effect that chronic liver disease has on a child's nutritional status and health is determined by the cause and severity of the liver disease and the age of onset. There is a bidirectional interaction between CLD and malnutrition: CLD often leads to malnutrition, and malnutrition adversely affects the course of liver disease.

The progressive loss of liver function and development of cirrhosis in children with CLD causes haemodynamic and metabolic disturbances and severe complications such as hepatopulmonary syndrome and renal failure. Liver transplantation is the only curative option for many children. For these children nutritional support improves quality of life, improves post-transplant survival, and prevents serious complications such as rickets, severe muscle loss, and haemorrhagic disease. In some children the liver disease requires specific nutritional therapy such as a galactose-free diet. However, even children with less severe liver disease require nutritional assessment and intervention to prevent osteopenia and the complications of micronutrient deficiency.

Current recommendations are based on our understanding of the effect of CLD on nutritional status, digestion and absorption of nutrients, metabolism and limited clinical trials.

\section{Prevalence of malnutrition}

Approximately $60-80 \%$ of children with CLD awaiting liver transplantation are malnourished; ${ }^{[1]}$ weight, height, head circumference, skinfold thickness and mid-upper-arm circumference are reduced. ${ }^{[2,3]}$ These changes are particularly prominent in children with severe cholestatic liver disease such as biliary atresia and the severe intrahepatic causes of CLD.

\section{Effect of malnutrition on prognosis}

The degree of malnutrition reflects the severity of liver disease and is included in the assessment of end-stage liver disease in children (paediatric end-stage liver disease (PELD) score). ${ }^{[4]}$ Malnourished children have increased post-transplant mortality and morbidity. ${ }^{[4]}$ In addition, specific nutrient deficiencies can cause serious complications, e.g. vitamin deficiencies (A, E, D, K) and essential fatty acid deficiency.

\section{Nutritional consequences of CLD}

CLD significantly alters body composition and metabolism. Fat mass is reduced and eventually lean body mass as well. Resting energy expenditure and total energy expenditure are increased by approximately $30 \%$ in young children with CLD. ${ }^{[5,6]}$ Children preferentially oxidise fat in the postabsorptive phase. ${ }^{[5,7]}$ Oxidation of branched-chain amino acids such as leucine is increased.

Hormonal changes contribute to poor growth and changes in body composition. Growth hormone receptor expression is reduced, leading to low insulin-like growth factor 1 (IGF-1). In adolescents, puberty is often delayed and hypogonadism is common. ${ }^{[8]}$

Considered together, these changes have important implications for nutritional support: energy intake should be high, periods of fasting avoided, protein intake not restricted, and branched-chain amino acids supplemented. Initiation of nutritional support should not be delayed as nutritional recovery may be difficult to achieve once children have developed severe malnutrition.

Liver-associated metabolic bone disease with pathological fractures is a significant complication in children with cirrhotic and non-cirrhotic CLD. ${ }^{[9]}$ The term 'hepatic osteodystrophy' describes 
this complex of structural and metabolic bone changes, including osteoporosis and osteomalacia or rickets in children.

Osteoporosis, where the bone mineral density (BMD) is decreased, is a common cause for fractures (prevalence $10-28 \%),{ }^{[8]}$ and although mostly asymptomatic, has a significant negative impact on morbidity and quality of life. ${ }^{[10]}$ In contrast to adults, children have a greater potential for spontaneous recovery of BMD after liver transplant, usually after 1 year. ${ }^{[8]}$ Immobility and low muscle force in this population further contribute to the low bone mass. ${ }^{[8]}$

In children, not only the existing bone is affected, but also the growth plates, adding rickets (the consequence of vitamin D deficiency on growing bone), spine abnormalities and growth failure to the equation. ${ }^{[8]}$ Vitamin D deficiency is thought to be a major causative factor for hepatic osteodystrophy. Malabsorption of fat-soluble vitamins due to deficient

\section{Table 1. Clinical nutritional assessment in paediatric chronic liver disease}

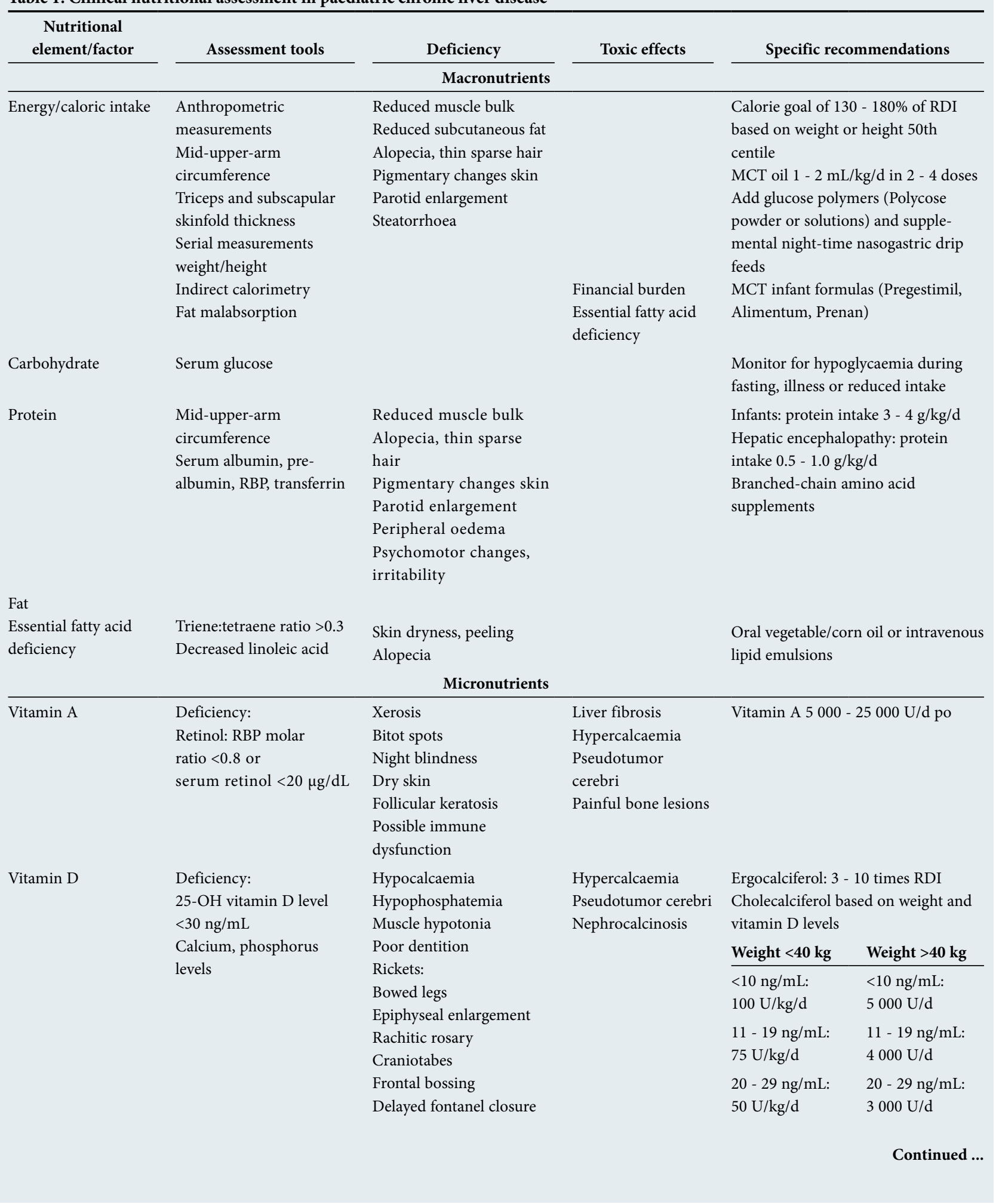


Table 1. (continued) Clinical nutritional assessment in paediatric chronic liver disease

\begin{tabular}{|c|c|c|c|c|}
\hline $\begin{array}{l}\text { Nutritional element/ } \\
\text { factor }\end{array}$ & Assessment tools & Deficiency & Toxic effects & Specific recommendations \\
\hline \multicolumn{5}{|c|}{ Micronutrients } \\
\hline Vitamin E & $\begin{array}{l}\text { Deficiency: } \\
\text { Vitamin E:total lipid ratio } \\
<0.6 \mathrm{mg} / \mathrm{g}(<1 \mathrm{y}) \\
<0.8 \mathrm{mg} / \mathrm{g}(>1 \mathrm{y})\end{array}$ & $\begin{array}{l}\text { Poor nerve conduction } \\
\text { Hypo/areflexia } \\
\text { Ataxia } \\
\text { Peripheral neuropathy } \\
\text { Loss of vibratory sense } \\
\text { Myopathy } \\
\text { Vision loss } \\
\text { Haemolytic anaemia }\end{array}$ & $\begin{array}{l}\text { Impaired neutrophil } \\
\text { chemotaxis } \\
\text { Potentiation } \\
\text { vitamin K deficiency } \\
\text { Coagulopathy } \\
\text { Diarrhoea } \\
\text { Hyperosmolality } \\
\text { (TPGS) }\end{array}$ & $\begin{array}{l}\text { Alpha-Tocopherol (acetate) } \\
25 \text { - } 200 \mathrm{IU} / \mathrm{kg} / \mathrm{d} \\
\text { TPGS (Luiqi E) } 15 \text { - } 25 \mathrm{IU} / \mathrm{kg} / \mathrm{d}\end{array}$ \\
\hline Vitamin $\mathrm{K}$ & $\begin{array}{l}\text { Deficiency: } \\
\text { Prolonged PTT/INR } \\
\text { Elevated PIVKA-II }\end{array}$ & $\begin{array}{l}\text { Haemorrhagic disease } \\
\text { Excessive bruising }\end{array}$ & & $\begin{array}{l}\text { Vitamin K } 2.5 \text { - } 5 \mathrm{mg}, 2 \text { - } 7 \text { times/wk } \\
\text { Intravenous vitamin K } 2 \text { - } 10 \mathrm{mg} \text { may } \\
\text { be required }\end{array}$ \\
\hline $\begin{array}{l}\text { Water-soluble } \\
\text { vitamins }\end{array}$ & & & & $\begin{array}{l}\text { Multivitamin preparation providing } \\
1 \text { - } 2 \text { times RDI }\end{array}$ \\
\hline \multicolumn{5}{|c|}{ Minerals and trace elements } \\
\hline Iron & $\begin{array}{l}\text { Deficiency: } \\
\text { Decreased iron level, } \\
\text { increased total iron- } \\
\text { binding capacity }\end{array}$ & $\begin{array}{l}\text { Pallor } \\
\text { Koilonychia } \\
\text { Stomatitis }\end{array}$ & $\begin{array}{l}\text { Teeth staining } \\
\text { Haemorrhagic } \\
\text { gastroenteritis } \\
\text { Metabolic acidosis } \\
\text { Coma, liver failure }\end{array}$ & Elemental iron 5 - $6 \mathrm{mg} / \mathrm{kg} / \mathrm{d}$ \\
\hline Zinc & $\begin{array}{l}\text { Deficiency: } \\
\text { Plasma zinc level } \\
<60 \mu \mathrm{g} / \mathrm{dL}\end{array}$ & $\begin{array}{l}\text { Alopecia, thin sparse hair } \\
\text { Acrodematitis } \\
\text { enterohepatica }\end{array}$ & $\begin{array}{l}\text { Decreased intestinal } \\
\text { absorption copper } \\
\text { and iron }\end{array}$ & $\begin{array}{l}\text { Zinc sulphate solution } 10 \mathrm{mg} / \mathrm{mL} \\
\text { elemental zinc } \\
\text { Elemental zinc } 1 \mathrm{mg} / \mathrm{kg} / \mathrm{d}\end{array}$ \\
\hline Selenium & $\begin{array}{l}\text { Deficiency: } \\
\text { Plasma selenium } \\
<40 \mu \mathrm{g} / \mathrm{L}\end{array}$ & & $\begin{array}{l}\text { Dermatological } \\
\text { changes } \\
\text { Diarrhoea } \\
\text { Dyspepsia } \\
\text { Anorexia }\end{array}$ & $\begin{array}{l}1-2 \mu \mathrm{g} / \mathrm{kg} / \mathrm{d} \text { oral sodium selenite or } \\
1-2 \mu \mathrm{g} / \mathrm{kg} / \mathrm{d} \text { selenium in TPN }\end{array}$ \\
\hline Magnesium & $\begin{array}{l}\text { Deficiency: } \\
\text { Serum magnesium } \\
<0.7 \mathrm{mmol} / \mathrm{L}\end{array}$ & & $\begin{array}{l}\text { Respiratory } \\
\text { depression } \\
\text { Lethargy } \\
\text { Coma }\end{array}$ & $\begin{array}{l}\text { Magnesium oxide } \\
0.5-1 \mathrm{mmol} / \mathrm{kg} \text { daily po, or } 50 \% \\
\text { solution of magnesium sulphate } \\
0.01-0.25 \mathrm{mmol} / \mathrm{kg} \text { IV over } 3-6 \mathrm{~h}\end{array}$ \\
\hline Calcium & $\begin{array}{l}\text { Deficiency in steatorrhoea } \\
\text { despite corrected } \\
\text { vitamin D status }\end{array}$ & Poor dentition & $\begin{array}{l}\text { Hypercalcaemia } \\
\text { Hypercalciuria }\end{array}$ & $\begin{array}{l}25-100 \mathrm{mg} / \mathrm{kg} / \mathrm{d} \text { up to } \\
800-1200 \mathrm{mg} / \mathrm{d}\end{array}$ \\
\hline Phosphorus & $\begin{array}{l}\text { Low serum phosphorus } \\
\text { level despite corrected } \\
\text { vitamin D and calcium } \\
\text { status }\end{array}$ & & $\begin{array}{l}\text { Gastrointestinal } \\
\text { intolerance }\end{array}$ & $25-50 \mathrm{mg} / \mathrm{kg} / \mathrm{d}$ up to $500 \mathrm{mg} / \mathrm{d}$ \\
\hline
\end{tabular}

intraluminal bile acids, decreased exposure to direct sunlight and poor 25-hydroxylation in end-stage liver failure, are all contributing factors. Secondary hyperparathyroidism, in response to low serum calcium, increases bone resorption and intestinal calcium absorption but also increases phosphate loss in the kidney.

Other contributing factors are suboptimal calcium intake, hypogonadism, vitamin $\mathrm{K}$ deficiency (important role in osteocalcin homeostasis), and corticosteroid treatment. ${ }^{[1]}$

\section{Causes of malnutrition}

The cause of malnutrition in CLD is multifactorial. Intake in children is poor, with as many as $70 \%$ of children consuming less than recommended. ${ }^{[2]}$ Nausea, anorexia, mucosal congestion, decreased intestinal motility, early satiety due to organomegaly and ascites, and dietary modifications that require unpalatable diets all contribute to reduced intake.

Infants and young children derive approximately $50 \%$ of their energy from dietary fat. Absorption of long-chain fatty acids is reduced as a result of reduced luminal bile acid concentration depriving children of this important source of energy and often leading to essential fatty acid deficiency. ${ }^{[12]}$

\section{Assessment of nutritional status}

The nutritional status of children is assessed to identify those who require additional nutrition support and monitor response to 
treatment. Nutritional status is assessed at the first and all subsequent visits.

A dietary history identifies the type and quantity of feeds taken. In the case of formula-fed infants calculation of daily intake is easier than in the toddler and older child on a mixed diet. Determining the variety of foods ingested is important as children with restricted diets are at risk of micronutrient deficiency. Asking parents to keep a dietary diary is useful to obtain this information. Symptoms such as vomiting, anorexia, diarrhoea or steatorrhoea, and pale stools further identify those children at risk of poor intake and malabsorption. Assessment of the nutritional status also includes assessment of subcutaneous fat and muscle mass and signs of micronutrient deficiency.

Anthropometry, the mainstay of nutritional assessment in most children, is influenced by changes in body composition in children with CLD. Weight-for-age and weight-for-height-for-age measurements usually underestimate the degree of malnutrition because of coexisting organomegaly, ascites and fluid retention. Stunting reflects chronic undernutrition; length or height should be accurately measured. However, in the presence of genetic conditions such as Alagille syndrome, stunting may be due to the underlying defect rather than malnutrition.

Skinfold thickness and mid-upper-arm circumference are less influenced by oedema and provide a more reliable estimate of nutritional status in these children. Skinfold thickness, measured over the triceps and subscapular areas, allows assessment of fat mass. These measurements require use of specialised calipers and appropriate training. Mid-upper-arm circumference is a useful tool that assesses muscle mass and can be compared with normal values for age.

Essential fatty acids or the triene:tetraene ratio can be determined in children with suspected essential fatty acid deficiency. These tests are often not available in routine laboratories in South Africa (SA).

Fat-soluble vitamin status should be assessed every 6 months or more frequently in the presence of deficiency. Biochemical vitamin A deficiency occurs before the deficiency becomes clinically overt. Serum retinol does not always accurately estimate vitamin A status in children with liver disease. The relative dose response may be more reliable but is not routinely performed. ${ }^{[13]}$ The molar ratio of plasma retinol:retinolbinding protein (RBP) has been suggested as an alternative (serum retinol $(\mu \mathrm{g} / \mathrm{dL}) /$ serum $\mathrm{RBP}(\mathrm{mg} / \mathrm{dL}) \times 0.0734$ : normal $0.8-2.0) ;^{[14]}$ results of studies assessing this measure are however equivocal and most laboratories in SA do not routinely determine RBP.

Children with CLD require regular assessment for evidence of vitamin $\mathrm{D}$ deficiency and bone disease. This includes a history of bone pain and fractures, palpation of the spine and assessment of pubertal stage. Laboratory evaluation would include $25-\mathrm{OH}$ vitamin $\mathrm{D}$, parathyroid hormone, calcium, phosphate, magnesium, and alkaline phosphatase. Hand X-rays are valuable to evaluate the severity of osteodystrophy and the growth potential. Dual-energy X-ray absorptiometry to detect low bone mass and lateral spine X-ray to determine the presence of vertebral fractures may be required in older children.

Vitamin E deficiency is common in cholestatic liver disease. Initially asymptomatic, children develop peripheral neuropathy, spinocerebellar degeneration, and ataxia. Early in the disease these changes are reversible but, if treatment is delayed, may become permanent. In the presence of hyperlipidaemia, a frequent finding in cholestatic liver disease, vitamin E levels may be falsely normal; the ratio of tocopherol:total lipids or tocopherol:cholesterol should therefore be assessed to screen for vitamin E deficiency.

Laboratories in SA do not determine protein induced in vitamin $\mathrm{K}$ absence (PIVKA) for vitamin K deficiency. Prothrombin time or international normalised ratio (INR) are frequently used to assess for vitamin $\mathrm{K}$ deficiency; it should be kept in mind that these measures are also influenced by liver synthetic function. The response to parenteral vitamin $\mathrm{K}$ supplementation indicates whether abnormalities are due to liver failure or vitamin $\mathrm{K}$ deficiency. Although coagulopathy is the major complication of vitamin $\mathrm{K}$ deficiency, bone disease may also be due to carboxylation defects in vitamin $\mathrm{K}$ deficiency.

Trace-element deficiency occurs in children with CLD. Zinc and selenium deficiencies are common and serum zinc levels should be determined in children who are not growing satisfactorily. Iron deficiency also commonly occurs, particularly in children with portal hypertension.

Plasma proteins (albumin, prealbumin, RBP) are less useful in children with CLD as their levels are influenced by hepatocellular function and systemic inflammation. Bioelectrical impedance has little value in the nutritional assessment of these children.

Table 1 summarises the clinical nutritional assessment of children with CLD.

\section{Nutritional support}

The goals of nutritional support in children with CLD are normal growth and body composition and the prevention of vitamin and trace-element deficiency. Nutritional support should not be delayed, particularly in young infants. Intake should be reviewed regularly. Severity of disease, presence of complications, levels of activity and age-related changes in nutritional requirements should be taken into account. This requires expertise that is often beyond the scope of the family physician and paediatrician. A dietitian, experienced in the management of children, should be involved early in the course of the child's disease.

In the absence of malnutrition, energy requirements can initially be considered to be normal. However, if growth is not satisfactory, high energy intake is encouraged. Intakes of $130-150 \%$ of normal energy intake are recommended. This is achieved by increasing fat and carbohydrate intake.

Increasing the fat intake increases total fat absorption. Mediumchain fatty acid absorption is not dependent on bile salts and diets are supplemented with these fatty acids. They should not exceed $80 \%$ of the total fat intake as essential fatty acid deficiency may ensue. Longchain polyunsaturated fatty acids are essential for normal growth and brain development. Diets are enriched with foods that are rich in these fatty acids, e.g. egg yolk and vegetable oils.

Carbohydrates are an important energy source in children. Diets should contain adequate carbohydrate to meet the child's energy requirements without causing osmotic diarrhoea. This is usually not a problem in children receiving normal foods; however, for those receiving enteral feeds, selection of a formula with glucose polymers and not sugars may be necessary. In children with galactossaemia, galactose-free diets are required.

Protein restriction limits normal growth and should be avoided. Intakes of 3 - $4 \mathrm{~g} / \mathrm{kg} /$ day (minimum $2 \mathrm{~g} / \mathrm{kg} /$ day) ${ }^{[14]}$ are encouraged. Although moderate elevations of ammonia are often present, this should not prompt prolonged protein restriction in the absence of encephalopathy.

Branched-chain amino acid supplementation has been shown to improve lean body mass gain. However, formulas enriched with these amino acids are expensive and are not readily available in SA.

Fat-soluble vitamin deficiencies frequently occur in children with cholestatic liver disease. This is predominantly due to fat malabsorption. These children often require high-dose supplementation and in some cases parenteral administration of vitamins. A watersoluble preparation of vitamin E (TPGS) improves the absorption of other fat-soluble vitamins. Unfortunately this preparation is not available in SA. 
Children are supplemented with 5000 - 10000 IU of vitamin A daily. Occasionally higher doses (up to $25000 \mathrm{IU} /$ day) are required, ${ }^{[1]}$ particularly in infants who have severe cholestatic liver disease. Care should be taken to avoid vitamin A toxicity which may cause pseudotumor cerebri, hypercalcaemia, painful bone lesions and liver toxicity.

Vitamin E deficiency is particularly difficult to treat in children with severe cholestasis. In the absence of TPGS, high-dose vitamin $\mathrm{E}$ supplementation is often required to prevent vitamin $\mathrm{E}$ deficiency. The starting dose is usually $10-25 \mathrm{IU} / \mathrm{kg} /$ day; this is increased as required to $100-200 \mathrm{IU} / \mathrm{kg} /$ day. Regular assessment of serum levels is required for dose titration.

Oral vitamin $\mathrm{K}$ supplementation is usually adequate to prevent severe vitamin $\mathrm{K}$ deficiency-associated coagulopathy. Children are given $2.5-5 \mathrm{mg} /$ day although supplementation three times per week is often adequate to prevent coagulopathy.

All children with CLD require vitamin D supplementation. The dose is determined by age, severity of liver disease, and the presence of complications such as rickets. Cholecalciferol is most frequently used to replenish vitamin $\mathrm{D}$ stores and prevent the complications of vitamin D deficiency. Alphacalcidol or calcitriol, active vitamin D metabolites, do not replace vitamin D stores, but are used to increase calcium absorption or to treat coexisting renal failure. These metabolites are usually added in children who have failed standard cholecalciferol supplementation and should not be used in isolation to treat vitamin D deficiency. Serum calcium and phosphate levels and urinary calcium should be monitored to avoid vitamin D toxicity. Children with vertebral fractures and evidence of low BMD may benefit from treatment with bisphosphonates and should be referred to bone specialists where possible..$^{[8]}$

Supplementation aims to maintain a serum $25-\mathrm{OH}$ vitamin D level of $>50 \mathrm{nmol} / \mathrm{L}$ and a parathyroid hormone of $<55 \mathrm{pg} / \mathrm{mL}$. Children with a $25-\mathrm{OH}$ vitamin $\mathrm{D}$ level $>25 \mathrm{nmol} / \mathrm{L}$ are given $3-10$ times the normal requirement (1 200 - $4000 \mathrm{U} /$ day); if the $25-\mathrm{OH}$ vitamin $\mathrm{D}$ level is $<25 \mathrm{nmol} / \mathrm{L}$, the dose is increased to $6000-25000 \mathrm{U} /$ day until normal levels are achieved. In the event of unsuccessful oral therapy, intramuscular vitamin $\mathrm{D}$ can be given monthly until normalisation of the serum vitamin $\mathrm{D}^{\left[{ }^{[8]}\right.}$

Dietary support of children with CLD also addresses trace element deficiency and sodium load. Supplementation with zinc, as well as other trace elements such as selenium, improves appetite and growth.

Sodium intake is restricted, particularly in those children with ascites. Fluid intake is not routinely restricted with the exception of children in hepatic failure.

\section{Routes of feeding}

Most children can be fed orally. Although liver-specific enteral feeds are not available in SA, modular feeds and other specialised infant formulas are useful in their management. Formulas developed for preterm infants have a high energy and mineral content and are enriched with medium-chain fatty acids. These formulas are often used to feed infants with cholestatic liver disease who are unable to breastfeed. Breastfed infants may require fortification or supplementation with medium-chain fatty acids.
Children with advanced liver disease require more frequent feeds as a result of rapid glycogen depletion in the fasting state and the risk of hypoglycaemia. These children often also have significant anorexia and require supplemental nasogastric feeds. Overnight nasogastric feeds are recommended in children who are unable to take in enough food to supply energy requirements. Nasogastric tubes are well tolerated by most of these children and do not increase the risk of bleeding in portal hypertension. If enteral feeds fail, parenteral nutrition is considered in consultation with a paediatric gastroenterologist and paediatric dietitian.

Although not an absolute contraindication, placement of a percutaneous endoscopic gastrostomy (PEG) is usually avoided in these children. Constant infusion feeds are given to children who are unable to tolerate bolus feeds. Regardless of the route or manner of feeding, oral feeding skills should be maintained to allow easier transition to full oral feeds at a later stage. The assistance of a speech and language therapist may be warranted.

\section{Conclusions}

Malnutrition is an important complication of CLD in children. Survival and quality of life are improved with early initiation of an active nutritional support programme. Most components of nutritional monitoring and supplementation can competently be implemented by the family physician and general paediatrician. However, given the complexity of the diseases, a paediatric gastroenterologist or hepatologist, together with a paediatric dietitian, should be involved in the treatment of these children from an early stage of their disease.

\section{References}

1. Young S, Kwarta E, Azzam R, Sentongo T. Nutrition assessment and support in children with end-stage liver disease. Nutr Clin Pract 2013;28(3):317-329. [http://dx.doi.org/10.1177/0884533612474043]

Chin SE, Shepherd RW, Thomas BJ, et al. The nature of malnutrition in children with end-stage liver 2. Chin SE, Shepherd RW, Thomas BJ, et al. The nature of malnutrition in children with
disease awaiting orthotopic liver transplantation. Am J Clin Nutr 1992;56(1):164-168.

disease awaiting orthotopic liver transplantation. Am J Clin Nutr 1992;56(1):164-168.
Sokol RJ, Stall C. Anthropometric evaluation of children with chronic liver disease. Am J Clin Nutr 1990;52(2):203-208

4. Los EL, Lukovac S, Werner A, Dijkstra T, Verkade HJ, Rings EH. Nutrition for children with cholestatic liver disease. Nestle Nutr Workshop Ser Pediatr Program 2007;59:147-157. [http://dx.doi. org/10.1159/000098533]

5. Greer R, Lehnert M, Lewindon P, Cleghorn GJ, Shepherd RW. Body composition and components of energy expenditure in children with end-stage liver disease. J Pediatr Gastroenterol Nutr 2003;36(3):358-363. [http://dx.doi.org/10.1097/00005176-200303000-00010]

Nightingale S, Ng VL. Optimizing nutritional management in children with chronic liver disease. Pediatr Clin North Am 2009;56(5):1161-1183. [http://dx.doi.org/10.1016/j.pcl.2009.06.005]

Mager DR, Wykes LJ, Roberts EA, Ball RO, Pencharz PB. Mild-to-moderate chronic cholestatic liver Mager DR, Wykes LJ, Roberts EA, Ball RO, Pencharz PB. Mild-to-moderate
disease increases leucine oxidation in children. J Nutr 2006;136(4):965-970.

8. Hogler W, Baumann U, Kelly D. Endocrine and bone metabolic complications in chronic liver disease Hogler W, Baumann U, Kelly D. Endocrine and bone metabolic complications in chronic liver disease
and after liver transplantation in children. J Pediatr Gastroenterol Nutr 2012;54(3):313-321. [http:// and after liver transplantation in children. J P
dx.doi.org/10.1097/mpg.0b013e31823e9412]

dx.doi.org/10.1097/mpg.0b013e31823e9412]
Suchy FJ, Sokol SR, Balistreri WF, eds. Liver Disease in Children: Cambridge University Press, 2014.

9. Suchy FJ, Sokol SR, Balistreri WF, eds. Liver Disease in Children: Cambridge University Press, 2014.
10. Mansueto P, Carroccio A, Seidita A, Di Fede G, Craxi A. Osteodystrophy in chronic liver diseases. Intern Emerg Med 2013;8(5):377-388. [http://dx.doi.org/10.1007/s11739-012-0753-5]

1. Pappa HM, Bern E, Kamin D, Grand RJ. Vitamin D status in gastrointestinal and liver disease. Cur Opin Gastroenterol 2008;24(2):176-183. [http://dx.doi.org/10.1097/mog.0b013e3282f4d2f3]

2. Socha P, Koletzko B, Swiatkowska E, Pawlowska J, Stolarczyk A, Socha J. Essential fatty acid metabolism in infants with cholestasis. Acta Paediatr 1998;87(3):278-283.

3. Feranchak AP, Gralla J, King R, et al. Comparison of indices of vitamin A status in children with chronic liver disease. Hepatology 2005;42(4):782-792. [http://dx.doi.org/10.1002/hep.20864]

14. Baker A, Stevenson R, Dhawan A, Goncalves I, Socha P, Sokal E. Guidelines for nutritional care for infants with cholestatic liver disease before liver transplantation. Pediatr Transplant 2007;11(8):825834. [http://dx.doi.org/10.1111/j.1399-3046.2007.00792.x]

15. Sultan MI, Leon CD, Biank VF. Role of nutrition in pediatric chronic liver disease. Nutr Clin Pract Sultan MI, Leon CD, Biank VF. Role of nutrition in pediatric chron
2011;26(4):401-408. [http://dx.doi.org/10.1177/0884533611405535]

6. Cameron R, Kogan-Liberman D. Nutritional considerations in pediatric liver disease. Pediatr Rev 2014;35(11):493-496. [http://dx.doi.org/10.1542/pir.35-11-493]
. Cameron R, Kogan-Liberman D. Nutritional considerations in

17. Murray KF, Horslen S, eds. Diseases of the Liver in Children. New York: Springer, 2014 